\title{
Orbital decompression for severe dysthyroid eye disease
}

\author{
PETER FELLS \\ From Moorfields Eye Hospital, City Road, London EC1V 2PD
}

SUMMARY Current methods of medical treatment of this difficult condition are briefly reviewed, with comments on the generally unsatisfactory response. Attention is therefore directed to surgical methods and a short history given of the various routes used for orbital decompression. The author's own results of transantral, and more recently ethmoidal, decompression are given, with a detailed description of the technique for the latter approach. An interesting frequent consequence of postoperative A pattern to the ocular movements is discussed in the light of Koornneef's concept of orbital fascial anatomy, and suggestions are made for its avoidance.

Severe dysthyroid exophthalmos is normally a bilateral disease in which both orbits are involved at the same time but in some patients the orbits are affected by the condition serially.

\section{MEDICAL THERAPY}

Over the years many methods of medical therapy have been tried in an attempt to control and reverse this sight threatening condition. The most successful of the medical treatments thus far has been the introduction of high dosage oral corticosteroids by Werner $^{1}$ in 1966, and doses of $120 \mathrm{mg}$ per day of prednisolone are commonly given in this manner. Unfortunately this very high dosage has to be maintained for a number of months, and many patients find that the complications of the therapy make it unacceptable. The addition of azathioprine has not permitted a significant reduction in the dosage of prednisolone required.

More recent attempts at therapy have included plasmapheresis, in which the immunoglobulins are washed out of the patient's system. ${ }^{2}$ Unfortunately when the plasmapheresis treatment ceases there is an enormous backswing and re-establishment of the condition, sometimes at more serious levels than those at the beginning of the therapy. The only successful use of plasmapheresis has been accompanied by high dose systemic prednisolone, and it is impossible to separate the effects of these two methods of therapy. Still more recently very encouraging reports for the use of oral cyclosporin $\mathrm{A}^{3}$

Correspondence to Peter Fells, FRCS, Moorfields Eye Hospital, City Road, London EC1V 2PD. have not been substantiated by other workers, including myself. Radiotherapy in carefully fractionated doses over a two-week period to the retrobulbar tissues in this condition does not yet have a regular place in the treatment of acute bilateral dysthyroid exophthalmos, because there is often a stage of initial increase in the swelling and chemosis, and again radiotherapy under these circumstances has to be accompanied by high doses of prednisolone. The role of radiotherapy with the linear accelerator in the less acute forms of still severe dysthyroid exophthalmos is being evaluated, but it appears to be offering worthwhile results. ${ }^{4}$

Acute severe dysthyroid exophthalmos threatens sight in two ways: the very high intraorbital pressure causes optic nerve failure, and it is probably mediated via compression of the blood supply to the optic nerve and the orbital tissues. The huge swelling of the extraocular muscles, which can so readily be visualised by $\mathrm{CT}$ scans $^{5}$ or magnetic resonance imaging techniques, shows the crowding at the orbital apex and the obvious effect on the many vital structures passing through that area. Vision may be under threat for other reasons. The gross proptosis in some cases prevents any degree of lid closure, so that there is chemosis, with drying of the cornea and conjunctiva, leading to exposure keratitis, corneal ulceration, and endophthalmitis. Here again there is an urgent need for more space to be created for the greatly increased orbital contents, namely the extraocular muscles and the orbital fat. Surgical decompression has been tried over many years in this condition. This article is a brief review of the 
techniques, with comments on my own current method of decompression and with a view to the future.

\section{SURGICAL DECOMPRESSION ROUTES}

Krönlein ${ }^{6}$ used a lateral approach to the orbit in 1888 to remove certain orbital tumours. This method was adapted for use in orbital decompression, and Kennerdell and Maroon ${ }^{7}$ have used it to allow dissection of all four orbital walls and give from $10-17 \mathrm{~mm}$ of improvement in the proptosis. The operation is often carried out on one side at a time, and many patients require simultaneous bilateral orbital decompression. It is not to be recommended as the best general approach to the condition.

In 1931 Naffziger $^{8}$ described orbital decompression into the anterior cranial fossa by removing the roof of the orbit on one side. The classical neurosurgical approach using frontal burr holes is employed, and the floor of the anterior cranial fossa is then removed, exposing the orbital contents. Access can be gained to both the lateral and the medial sides of the orbit by this approach, but there are many important anatomical structures in the superior orbit that have to be avoided when this route is used. Some cynics have claimed that the exophthalmos is replaced by pulsating exophthalmos, since the orbital contents are put into contact with the intracranial tissues, and the degree of decompression achieved is small.

In the 1930s a number of workers used the inferior orbital approach for decompression, and Walsh and Ogura $^{9}$ published a large series in which the Caldwell-Luc transantral approach allowed removal of the inferior and medial walls of the orbit for decompression. In 1967 Freedman and Barrie Jones ${ }^{10}$ reported the use of this technique in a patient who had undergone Naffziger transfrontal orbital decompression three months previously but in whom visual acuity and the visual fields had deteriorated again, threatening his sight. These workers commented particularly on the advantages of binocular microscopical dissection via this rather deep hole to permit good removal of the medial wall of the orbit up to the level of the cribriform plate, and also of the medial half of the floor of the orbit. Professor Barrie Jones's earlier experience with surgery of the sinuses and facial bones enabled him to use this technique successfully.

I learned this method when working with Professor Barrie Jones on the Professorial Unit in 1968 and also his later technique of the extended lateral orbitotomy, which was used primarily to allow optimal access to orbital tumours. ${ }^{11}$ It is worth noting in passing that this extended lateral orbitotomy was used on a patient with $30 \mathrm{~mm}$ of unilateral proptosis, which in those days was considered could not be the result of dysthyroid eye disease alone but must indicate a tumour within the orbit. ${ }^{12}$ In fact the very extensive dissection carried out on the patient enabled us to identify the enormously enlarged rectus muscles and also to confirm that there was no orbital tumour. Improved diagnostic methods that are now available to us would prevent such surgery being undertaken for a dysthyroid patient.

DeSanto ${ }^{13}$ is the present worker with the greatest experience of transantral decompression for thyroid eye disease, and he too uses the binocular microscope and removes all the orbital floor, both medial and lateral, to the infraorbital nerve. When all the bony tissue has been removed, the periosteum is then incised, allowing the decompression to occur.

I started by doing transantral decompression via the Caldwell-Luc approach for my first series of patients with dysthyroid eye disease.$^{14}$ With the first 15 transantral decompressions 12 were bilateral and ocular motor imbalance followed in four of them, but in only one of these was later ocular muscle surgery required for persistent diplopia. It is interesting to note that in a series of 200 transantral decompressions by DeSanto diplopia followed in 159 patients.

\section{Material and methods}

I have now changed to an anterior ethmoidectomy for decompression because I think that this allows better optic nerve decompression. The CT scan taken in the horizontal plane (Fig. 1) shows not only the crowding of tissue at the orbital apex but also the

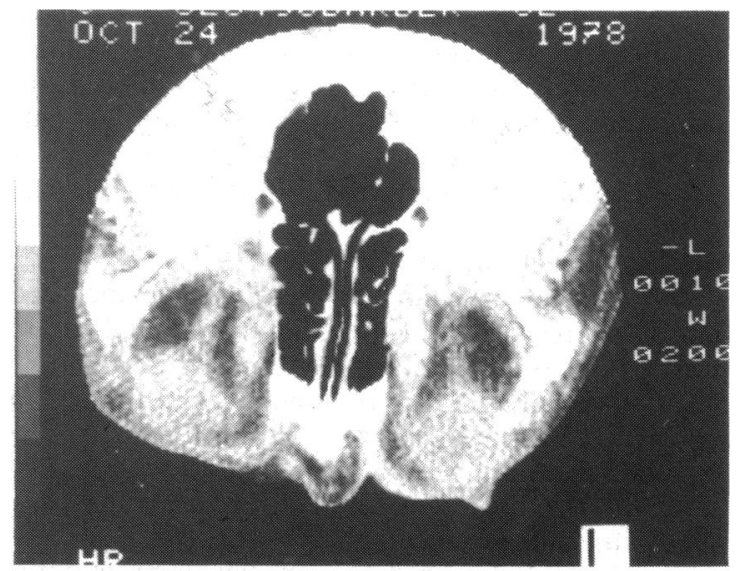

Fig. 1 CT scan in horizontal plane of patient with bilateral, severe dysthyroid eye disease. The enlarged muscles are causing optic nerve compression at the orbital apex, particularly on the left side. The left medial rectus muscle is also bulging the ethmoidal wall medially, that is, attempting autodecompression. 


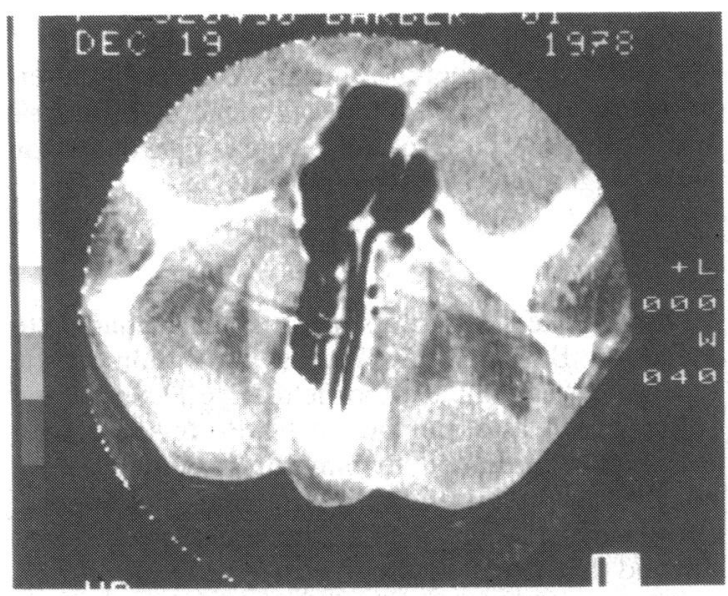

Fig. 2 The same patient after left ethmoidal decompression. Note the medial rectus displacement into the ethmoids and the extra space at the orbital apex. Compare with the unoperated right side.

inward bowing of the lateral walls of the ethmoidal sinuses. This is really the beginning of autodecompression. The volume of the ethmoidal space is usually larger than that of the antrum in most Caucasians and it would seem that the most important part of the decompression may best be achieved via the medial wall. I carry out this operation with my ear, nose, and throat colleague, Mr B H Pickard, who makes a skin incision high on the side of the nose and then strips the periosteum and the orbital contents laterally before clearing the ethmoidal cells away, going up as high as the cribriform plate and then moving across to take the medial half of the orbital floor. I rarely ask him to try to go across the whole of the orbital floor, but occasionally it is necessary to unroof the infraorbital nerve and move across lateral to the orbital nerve when maximum decompression is essential. My ENT colleague's reluctance to carry out this ethmoidectomy as a simultaneous bilateral procedure has been overcome since he has never yet had any signs of ischaemia of the tip of the nose, which he thought initially was a real risk. Once the bony space has been created I incise the periosteum from posterior to anterior above the upper border of the medial rectus, below the medial rectus, and again in the inferiomedial part of the orbit parallel to the medial side of the inferior rectus. These three longitudinal incisions then have openings with lacrimal sac scissors in the coronal plane to make $\mathrm{H}$-shaped flaps to allow maximum herniation of orbital fat (Figs. 2, 3).

\section{Results}

It has been apparent that adequate decompression is

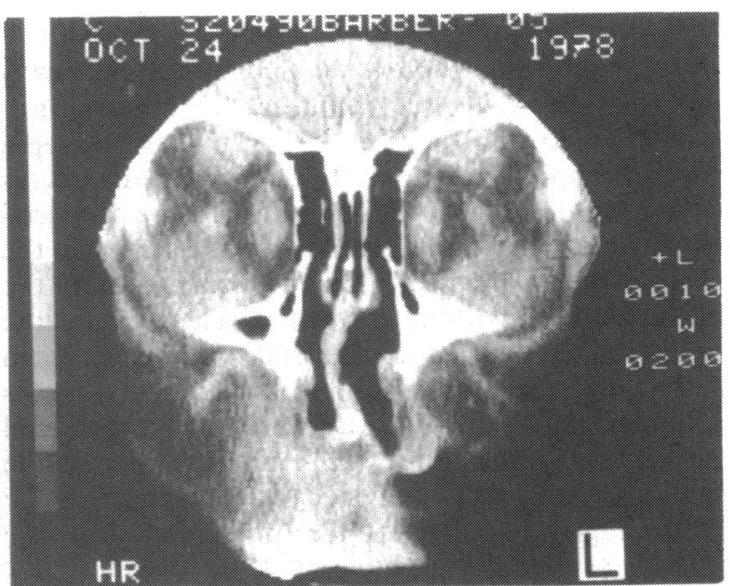

Fig. 3a

Figs. 3 (a) and (b) The same patient shown in the coronal plane (a) before, and (b) after left ethmoidal decompression.

obtained by this means, with an average $4 \mathrm{~mm}$ of decompression being achieved on each side. What is of great interest to me is that, out of 14 patients who had such anterior ethmoidal decompressions, 11 had changes in their ocular movements. ${ }^{15}$ In eight of them there was an A pattern of esotropia, one of them had an A pattern of exotropia, and two had esotropia. In some of these patients the esotropia was only temporary, but in many of them it persisted, and later ocular muscle surgery was required to restore binocular single vision.

\section{Discussion}

It is interesting to speculate on the probable causes of this very consistent pattern in the alteration of ocular

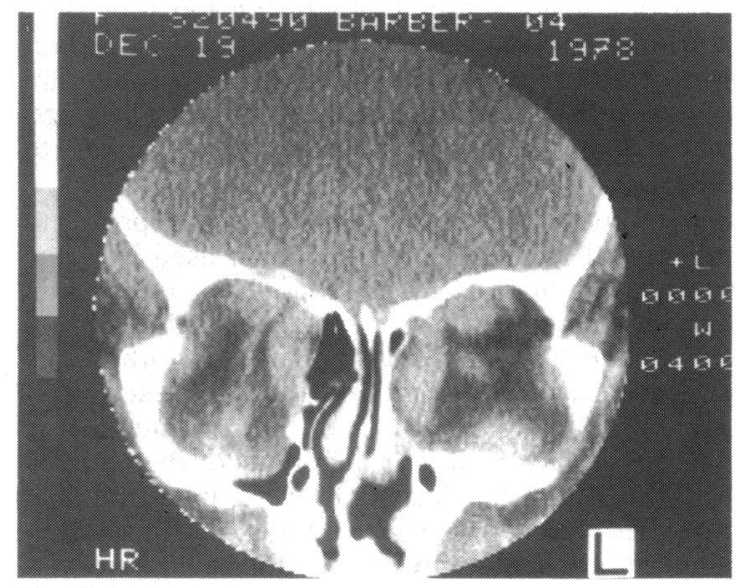

Fig. 3b 
movements by the anterior ethmoidal decompression. I think that the explanation lies in our newly acquired knowledge of orbital fascial anatomy provided by Koornneef. The connective tissue septa from the upper and lower edges of the medial rectus muscle to the roof and floor of the orbit are displaced by the increased orbital fat and are incised when the longitudinal periosteal incisions are made. At the same time the orbital tension is released and the globe is pulled back into the orbit, but the increased mechanical advantage allowed to the medial rectus produces the esotropia. Because the longitudinal incision by the inferior rectus is only on its medial side and not on the lateral side of that muscle, the persisting connections of the orbital fascia on the lateral side of the inferior rectus do not allow the lower part of the globe to be pulled into such an esotropic position, and hence have a tendency to an A pattern. The increase in esotropia following surgery allows for an enhanced vertical action of the superior oblique, and this again produces an $\mathrm{A}$ pattern to the movements.

The reasons for orbital decompression have altered somewhat over the years. Initially they were only ever carried out for patients with sight threatening disease. Other indications in some surgeons' hands include decompression as a preliminary to ocular muscle surgery when there are more than $25 \mathrm{~mm}$ of proptosis bilaterally, which would in fact be further increased if ocular muscle recessions were carried out to improve the diplopia. ${ }^{13}$ Some patients who cannot tolerate prolonged therapy with high dose prednisolone may also elect for orbital decompression to enable them to stop taking prednisolone. Younger patients in whom the proptosis has been of gradual onset and who may have quite white eyes without chemosis or conjunctival injection, but yet have marked bilateral proptosis with very wide palpebral fissures, are greatly handicapped by their appearance and request cosmetic surgery. Surgeons with wide experience in orbital decompression are now prepared to offer the treatment to such patients, though later ocular muscle surgery and lid surgery to deal with lid retraction may be required.

In more recent times Tessier's surgical approach to the frontal facial skeleton has been used by some surgeons for orbital decompression. The frontal skin flap is stripped down from the scalp bilaterally to expose the whole of the front of each orbit. The periorbita can then be freed on all sides of each orbit, and the relieving incisions into the periosteum may then be placed in all four quadrants of the globe in between where the rectus muscles run. Koornneef has used this approach, and his personal communication suggests that he is not having any significant alteration in ocular muscle balance by this procedure. This is presumably because there is a symmetrical and therefore more nearly equal alteration in all quadrants without a tendency to produce a bias towards A pattern of esotropia. This operation takes longer but may prove to be the best.

\section{Conclusion}

I should like to express my personal thanks to Professor Barrie Jones for his inspiration to me during my training at Moorfields Eye Hospital and subsequently as a member of his Professorial Unit team. I am indebted to him for his emphasis on anatomical understanding before devising surgical approaches to deal with particular problems, but beyond that I shall always be grateful to him for his teaching on the approach to the patient as a person and not merely as a case of some interesting condition. Our present lack of any adequate means to prevent ocular involvement in thyroid eye disease, which has such a very prolonged and distressing natural history over years, means that these essential old-fashioned attributes of the doctor have to be exercised to their fullest extent in the management of these unfortunate patients.

The beautiful CT scans are by courtesy of Dr Glyn Lloyd, of Moorfields Eye Hospital.

\section{References}

1 Werner SC. Prednisone in emergency treatment of malignant exophthalmos. Lancet 1966; i: 1004-7.

2 Dandona P, Marshall N, Bidey SP, Nathan A, Havard CWH. Successful treatment of exophthalmos and pretibial myxoedema with plasmapheresis. Br Med J 1979; i: 374-6.

3 Weetman AP, McGregor AM, Ludgate M, et al. Cyclosporin improves Graves' ophthalmopathy. Lancet 1983; ii: 486-9.

4 Pinchera A, Bartalena L, Chiovato L, Marcocci C. Radiotherapy of Graves' ophthalmopathy. In: Gorman CA, Waller RR, Dyer JA, eds. The eye and orbit in thyroid disease. New York: Raven Press, 1984: 301-16.

5 Fells P, Waddell E. Ocular involvement in dysthyroid disease. In: Tsamparlakis J, ed. Secondary strabismus-Proceedings of the 10th Meeting of the Concilium Europaeum Strabismi Studio Deditum. Athens: 1970: 83-9.

6 Krönlein RU. Zur Pathologie und operativen Behandlung der Dermoidcysten der Orbita. Bruns' Beitr Klin Chir 1888; 4: 149-63.

7 Kennerdell JS, Maroon JC. An orbital decompression for severe dysthyroid exophthalmos. Ophthalmology (Rochester) 1982; 89: 467-72.

8 Naffziger HC. Progressive exophthalmos following thyroidectomy: its pathology and treatment. Ann Surg 1931; 94: 582-6.

9 Walsh TE, Ogura JH. Transantral orbital decompression for malignant exophthalmos. Laryngoscope 1957; 67: 544-68.

10 Freedman A, Jones BR. Surgical problems in dysthyroid eye disease. Trans Ophthalmol Soc UK 1967; 87: 431-43.

11 Jones BR. Surgical approaches to the orbit. Trans Ophthalmol Soc UK 1970; 90: 269-81.

12 Fells P, Jones BR. A vermiculating tumour of the orbit. Trans Ophthalmol Soc UK 1970; 90: 289-93. 
13 DeSanto LW. Transantral orbital decompression. In: Gorman CA, Waller RR, Dyer JA, eds. The eye and orbit in thyroid disease. New York: Raven Press 1984: 231-51.

14 Fells P. Surgical decompression of the orbit. In: Werner SC, Ingbar SH, eds. The thyroid. 4th ed. Hagerstown: Harper and Row, 1978: 682-3.
15 Fells P, McCarry B. In: Transactions of 5th Congress of the International Strabismological Association in press.

16 Koornneef L. Spatial aspects of orbital musculofibrous tissue in man. Amsterdam and Lisse: Swets and Zeitlinger, 1977. 